\title{
Study of Cylindrical Honeycomb Solar Collector
}

\author{
Atish Mozumder, ${ }^{1}$ Anjani K. Singh, ${ }^{2}$ and Pragati Sharma ${ }^{2}$ \\ ${ }^{1}$ Motilal Nehru College, University of Delhi, Benito Juarez Marg, New Delhi 110021, India \\ ${ }^{2}$ Department of Applied Sciences, Bharati Vidyapeeth's College of Engineering, A 4 Paschim Vihar, New Delhi 110063, India
}

Correspondence should be addressed to Anjani K. Singh; anjaninsit@gmail.com

Received 10 January 2014; Revised 4 April 2014; Accepted 15 April 2014; Published 12 May 2014

Academic Editor: Charles Michael Drain

Copyright (C) 2014 Atish Mozumder et al. This is an open access article distributed under the Creative Commons Attribution License, which permits unrestricted use, distribution, and reproduction in any medium, provided the original work is properly cited.

\begin{abstract}
We present the results of our investigation on cylindrical honeycomb solar collector. The honeycomb has been fabricated with transparent cellulose triacetate polymer sheets. Insulation characteristics of the honeycomb were studied by varying the separation between the honeycomb and the absorber plate. The optimal value of the separation was found to be $3.3 \mathrm{~mm}$ for which the heat transfer coefficient is $3.06 \mathrm{~W} \mathrm{~m}^{-2} \mathrm{~K}^{-1}$. This supports result of previous similar experiments. Further we test the honeycomb through a field experiment conducted in Delhi $\left(28.6^{\circ} \mathrm{N}, 77^{\circ} \mathrm{E}\right)$ and found that when the incident angle of the solar radiation is within $20^{\circ}$ then the performance of the system with the honeycomb is better than the one without the honeycomb.
\end{abstract}

\section{Introduction}

A solar collector converts the solar energy into useful heat in the most efficient way. The solar collector absorbs the whole of the spectrum, unlike the photovoltaic cell which converts a part of the solar spectrum. However the efficiency of solar collectors is low as a large fraction of heat is dissipated [1]. The most significant part of heat loss from a solar thermal device is due to convection [2]. The most important challenge connected with solar collector is to reduce this loss of heat from the collector surface which may be as high as $40 \%$ [3] and therefore it has attracted the attention of scientists working in this area. In order to reduce this heat loss, generally one or more transparent plates are used to cover the collector surface. In more recent devices the space between the collector surface and the cover plate is evacuated. This makes the manufacture of solar devices expensive and energy intensive. Furthermore, the maintenance of vacuum poses additional problem for large collector surfaces that are required for building or for industrial applications.

The other alternative which has been explored since the 1970 s is to use a honeycomb layer between the cover plate and the collector plate $[4,5]$. The honeycomb suppresses the convection and also reduces the loss of energy due to radiation while it allows the solar energy to go through. Many variations of honeycomb have been attempted. These are classified as transparent insulation materials (TIM). A good review of such materials can be found in the paper by Wong et al. [6].

The honeycombs have been applied for water heating, air heating, and building application like windows [710]. In Israel, panels fitted with honeycombs are available commercially. In countries like India, the full potential of honeycombs has not been fully utilized. Honeycombs can make the solar cookers more effective by efficiently absorbing the solar energy during the day and retaining the heat till late afternoon and evening. The hot supper can be served directly from the solar cooker chamber without reheating. Most of the honeycombs investigated so far were with rectangular or square channels [11], fabricated with thick and hard materials. Zhang et al. [12] studied transparent cylindrical honeycomb structure with thin-walled glass tube as the honeycomb unit and applied to a flat-plate solar collector.

In the present investigation the honeycomb has been fabricated with transparent material of cellulose triacetate polymer sheets of thickness $0.1 \mathrm{~mm}$. The thin material has the advantage that it absorbs less solar radiation [13]. However it is difficult to construct a stable structure of square honeycombs with such thin material. Therefore we designed a cylindrical honeycomb using thin transparent sheets and 
investigated its properties in order to find its suitability in solar applications. The gap between the honeycomb layer and the collector plate plays a very crucial role in controlling the convective heat loss. A number of studies have also been reported on the effect of gap thicknesses between the honeycomb layer and the collector plate and also the gap between the cover plate and the honeycomb. Abou-Ziyan and Richards [14] presented results of an experimental study on the effect of the thickness of gaps between honeycomb and absorber plate and honeycomb and cover plate on the total heat transfer across a compound honeycomb and concluded that, even for relatively thick air gaps, the rectangular-cell compound honeycomb is found to be an effective convection suppressor. A compound honeycomb with air gaps above and below the honeycomb is shown to be superior in suppressing convection to a compound honeycomb of equal total thickness with only one air gap below the honeycomb.

In a recent paper Ghoneim [11] has reported detailed experimental investigations on a square-shaped honeycomb. They have tested the performance of a honeycomb collector using a water heater. In another paper Abdullah et al. [15] presented the results of an experimental investigation on the performance of solar collectors outfitted with honeycombs of different arrangements. They concluded that the bottom gap is the crucial factor that controls the heat transfer coefficient.

\section{Design and Fabrication of the Honeycomb}

The honeycomb has been constructed using transparent and flexible cellulose triacetate polymer sheets of thickness $0.1 \mathrm{~mm}$. Tubes of inner diameter $1.1 \mathrm{~cm}$ and height $5.4 \mathrm{~cm}$ were made using pieces of the transparent sheets $(7.5 \mathrm{~cm} \times$ $5.4 \mathrm{~cm}$ ) by winding it on a metallic cylinder of diameter $1.1 \mathrm{~cm}$ and fixing the ends by transparent adhesive tapes. A row of tubes were pasted on a $30 \mathrm{~cm}$ long and $5.4 \mathrm{~cm}$ wide rectangular strip of the same material by using transparent adhesive. On the first row of tubes a second rectangular strip was pasted. In this way rows of tubes and straight strips were pasted alternately to make the honeycomb. A total of 625 tubes and 25 straight strips of transparent polymers were used to make a honeycomb of dimension $30 \mathrm{~cm} \times 30 \mathrm{~cm} \times 5.4 \mathrm{~cm}$. The honeycomb was placed in a square frame of height $6 \mathrm{~cm}$ and inner dimensions $30 \mathrm{~cm} \times 30 \mathrm{~cm}$ which is made of transparent acrylic sheets of thickness $2.23 \mathrm{~mm}$. The cover plate used was made of transparent acrylic sheet of thickness $1.54 \mathrm{~mm}$. Galvanized iron (GI) sheets $(30 \mathrm{~cm} \times 30 \mathrm{~cm})$ of thickness $0.51 \mathrm{~mm}$ painted with acrylic black paint were used as absorber plates. The honeycomb thus constructed with aspect ratio 4.9 is shown in Figure 1.

Another identical collector was constructed without the honeycomb layer which is referred to as "reference collector." The reference collector has an identical collector plate, a frame, and a cover plate.

\section{Heat Insulation by the Honeycomb}

In the first part of the investigations we attempted to find out the gap between the honeycomb and the collector plate $\left(L_{b}\right)$

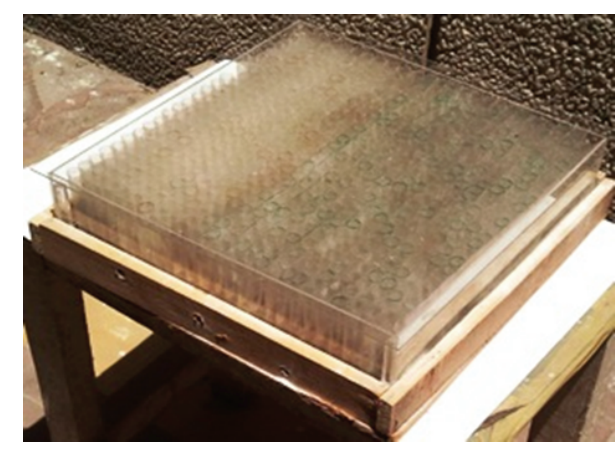

FIGURE 1: Picture of the honeycomb along with the wooden vessel to carry out field investigation.

that is most effective in retaining the heat of the collector plate. This has been done in the laboratory. We heated the collector plates of the honeycomb collector and the reference collector by using an electrical oven maintained at $60^{\circ} \mathrm{C}$. After keeping the plates in the oven for a sufficient time, the first plate was transferred below the honeycomb layer and the other to the reference collector. For each one of the collectors we used polystyrene hollow boards of thickness $1 \mathrm{~cm}$ to eliminate the dissipation of heat from bottom. The wooden base which contains a gypsum layer as shown in Figure 1 was not used for this part of the experiment. In the honeycomb collector the gap between the collector plate and honeycomb layer was maintained by using pieces of acrylic sheets which are referred to as "gap support" in the text. Rectangular pieces $(20 \mathrm{~mm} \times 3 \mathrm{~mm})$ of acrylic polymer sheets of thicknesses $2.70 \mathrm{~mm}, 3.28 \mathrm{~mm}$, and $3.82 \mathrm{~mm}$ were successively introduced between the collector plate and the honeycomb structure. The pieces were kept at four corners and around the center of the collector plate. While the plates cooled by dissipating heat, readings of temperature of the plates were taken using thermocouples and the digital thermometers, which were standardized using steam temperature. Readings were recorded manually every two minutes for duration of 20 minutes. Six sets of observations were obtained for each value of the gap as listed and for the reference collector. The temperature decays exponentially in each case [16]:

$$
z=\frac{T(t)-T_{\infty}}{T_{0}-T_{\infty}}=e^{-(h A / \rho c V) t}
$$

The plots of $\ln z$ against time, for the different gap supports and for a reference collector which had no honeycomb layer, are shown in Figures 2(a), 2(b), 2(c), and 2(d). Straight lines fitted to each one of the graphs show that the temperature decays according to the expression (1). In Table 1 we have summarized the values of heat transfer coefficients (h) obtained. We observe that the value of heat transfer coefficient for gap $L_{b}=3.28 \mathrm{~mm}$ is the least. Comparing the values of $h$ for different gap thicknesses and for the reference collector, we observe that when the gap is not optimal at $3.3 \mathrm{~mm}$, the value of $h$ approaches that of the reference collector. 


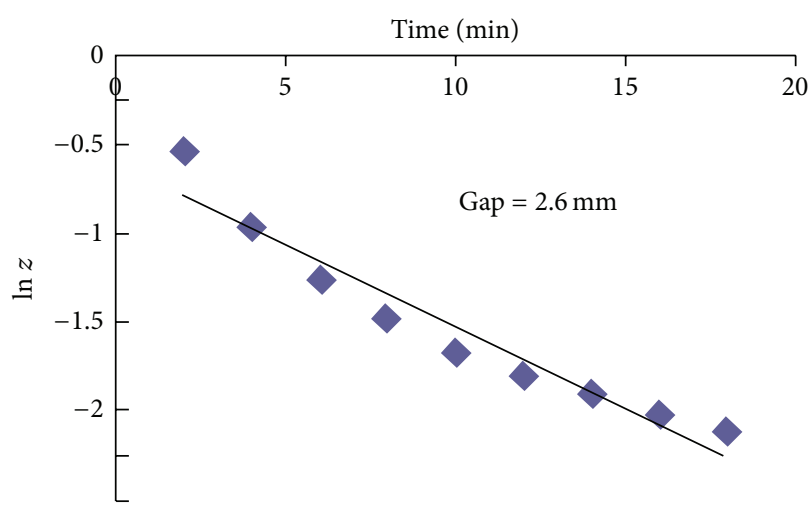

(a)

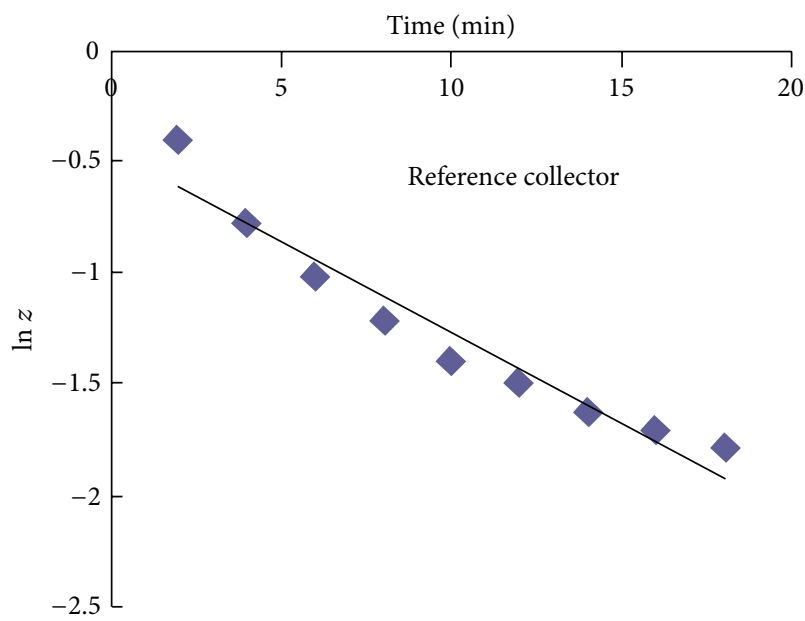

(c)

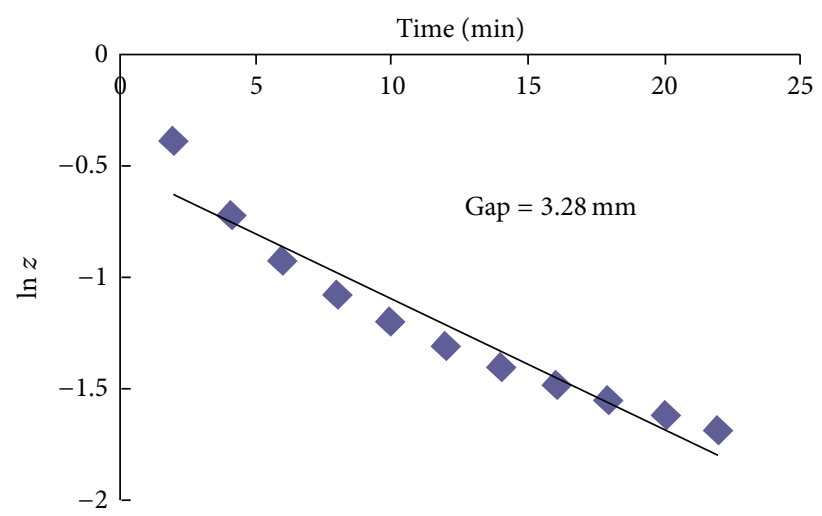

(b)

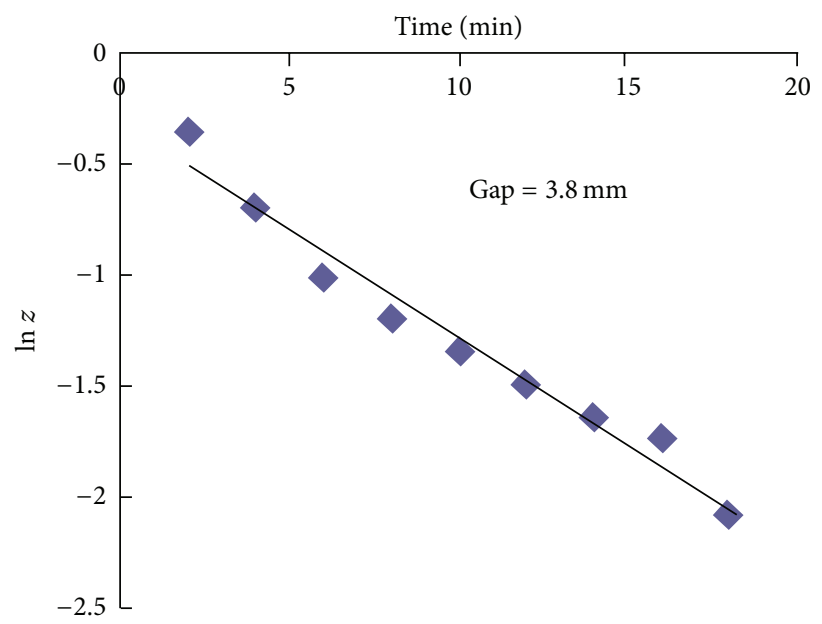

(d)

FiguRE 2: Graph of $\ln z$ and time for different gap support for honeycomb and reference collector.

TABLE 1: The values of $R^{2}$ and convective heat transfer coefficients with respect to gap between the honeycomb and the plates. The errors shown are statistical.

\begin{tabular}{lcc}
\hline Gap $\left(L_{b}\right)(\mathrm{mm})$ & $R^{2}$ & $\begin{array}{c}\text { Convective heat transfer coefficient } \\
\left(\mathrm{W} \mathrm{m}^{-2} \mathrm{~K}^{-1}\right)\end{array}$ \\
\hline $2.70 \pm 0.02$ & 0.932 & 4.2 \\
$3.28 \pm 0.06$ & 0.927 & 3.06 \\
$3.82 \pm 0.02$ & 0.953 & 4.38 \\
Reference & 0.934 & 4.4 \\
\hline
\end{tabular}

In a similar field experiment Ghoneim [11] found that by using square honeycomb of aspect ratio 6 the efficiency of solar energy conversion is the maximum for gap of $3.2 \mathrm{~mm}$.

\section{Solar Energy Conversion in the Honeycomb Collector}

In this section we describe the field experiment which we conducted in order to compare the collection efficiency of the honeycomb collector with the reference collector having a single cover plate. Two square vessels of inner dimension
$30 \mathrm{~cm} \times 30 \mathrm{~cm}$ and depth of $4.0 \mathrm{~cm}$ were constructed using wooden boards of $1 \mathrm{~cm}$ thickness. These were filled with $2 \mathrm{~kg}$ gypsum powder that was spread uniformly. The collector plates were placed on the top of the gypsum layer. In the honeycomb collector, the gap between the honeycomb and the collector plate was maintained by milled cylindrical wooden pieces of average diameter $3.25 \mathrm{~mm}$. The wood was preferred as the acrylic deforms at the temperatures that prevail on the collector surface. Square frames and cover plates as described in Section 2 were used for covering the collectors from the sides and the top, respectively.

The experiment has been conducted in Delhi $\left(28.6^{\circ} \mathrm{N}\right.$, $77^{\circ} \mathrm{E}$ ) where the hottest months are May and June. During this period of the year the day temperature often goes beyond $45^{\circ} \mathrm{C}$. Temperatures were recorded simultaneously at seven points, namely,
(a) the ambient air in the sun,
(b) at the bottom of the collector plates of the two systems,
(c) bottom of gypsum layer of the two systems,
(d) the cover plates of the two systems. 
TABLE 2: The median values of hourly solar radiation for the month of May [16], the values of angle of incidence of the beam radiation on the flat plate with local time (calculated for May, 22) according to the procedure detailed by Duffie and Beckman [17], and the values of transmittance $\tau(\theta)$ calculated for $10 \mathrm{hrs}$ and $11 \mathrm{hrs}$.

\begin{tabular}{|c|c|c|c|c|c|c|c|c|c|c|c|c|}
\hline Local time (hr) & 7 & 8 & 9 & 10 & 11 & 12 & 13 & 14 & 15 & 16 & 17 & 18 \\
\hline $\begin{array}{l}\text { Hourly global solar } \\
\text { radiation, } \mathrm{H}_{\mathrm{n}}\left(\mathrm{kW} \mathrm{h} / \mathrm{m}^{2}\right)\end{array}$ & 0.18 & 0.40 & 0.59 & 0.78 & 0.90 & 0.94 & 0.93 & 0.88 & 0.76 & 0.56 & 0.38 & 0.17 \\
\hline Incident angle, $\theta$ & - & - & $45.5^{\circ}$ & $32.4^{\circ}$ & $19.6^{\circ}$ & $9.3^{\circ}$ & $12.5^{\circ}$ & $24.6^{\circ}$ & $37.6^{\circ}$ & $50.7^{\circ}$ & - & - \\
\hline Transmittance, $\tau(\theta)$ & - & - & - & 0.13 & 0.17 & - & - & - & - & - & - & - \\
\hline
\end{tabular}

TABLE 3: The value of angle of incidence of the beam radiation on the fifteenth day for all months of the year at the solar noon.

\begin{tabular}{|c|c|c|c|c|c|c|c|c|c|c|c|c|}
\hline Month & Jan & Feb & Mar & Apr & May & Jun & Jul & Aug & Sep & Oct & Nov & Dec \\
\hline Incident angle (degree) & 49.9 & 41.4 & 31.0 & 19.0 & 10.5 & 7.5 & 8.5 & 15.1 & 26.8 & 38.4 & 48.1 & 52.4 \\
\hline
\end{tabular}

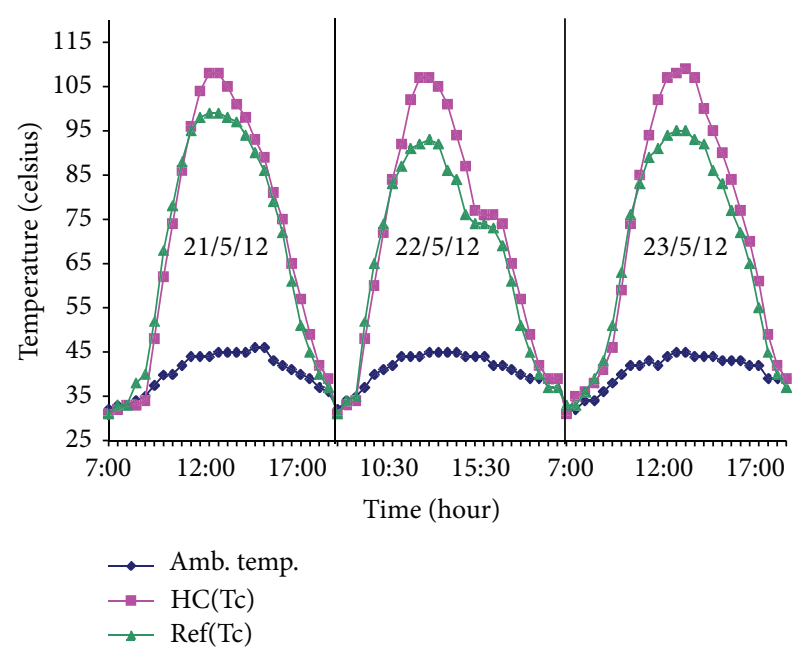

Figure 3: The variation of temperatures of collector plates of honeycomb collector, reference collector, and ambient air with the local time shown for three successive days.

The cover plate temperatures were recorded by digital thermometer while for all other measurements mercury thermometers (with accuracy of $0.5^{\circ} \mathrm{C}$ ) were used. The data were recorded manually in an interval of $30 \mathrm{~min}$. The two set ups were placed in an open area near the laboratory which receives sunlight throughout the day. The ambient temperature was recorded adjacent to the experimental setups at a height of $1 \mathrm{~m}$ from the ground. Observations were recorded continuously on successive days from morning 7 am to late evening 8 pm except Saturday, Sunday, and other holidays. On some days sky remained partially clouded or dust storm held up the experiment. A total of 35 days of observations could be recorded from which the inferences were drawn.

We have shown in Figure 3 the variation of the collector temperature of the honeycomb collector and the reference collector for three successive days. For other days the pattern is similar with difference in the peak temperature which varies from $105^{\circ} \mathrm{C}$ to $108^{\circ} \mathrm{C}$ depending on the weather conditions. The collector with honeycomb gives substantially higher temperature as compared to the collector without honeycomb from 12 noon to $2 \mathrm{pm}$. The peak to peak temperature difference between the honeycomb collector and reference collector has been found to be between $9^{\circ} \mathrm{C}$ and $12^{\circ} \mathrm{C}$.

The graphs of temperature variations show that in the morning hours the collection efficiency of the honeycomb collector is lower than that of the reference collector. Around 11 am the two collectors have nearly equal value of collection efficiency. From 12 noon to 1:30 pm the honeycomb collector delivers substantially higher temperatures. From 3 pm till late in the afternoon the honeycomb collector plate temperature remains marginally higher than the reference collector. By next morning the two collector plates are at the same temperature.

From 12 noon till $1 \mathrm{pm}$ the angle of incidence of the sunlight is within $10^{\circ}$ as can be seen from Table 2. During this period the honeycomb collector plate receives the solar flux directly. The significantly higher temperature for the honeycomb collector happens because of the heat loss suppression from the top surface. Both convective as well as radiative losses are suppressed. The radiation becomes significant as temperature rises and its suppression by the honeycomb layer results in higher temperature of the collector plate. However during the morning hours when the incidence angle of the sun is beyond $20^{\circ}$ the efficiency of the honeycomb collector is below the collector without the honeycomb.

The energy conversion efficiency, which is defined as the ratio of useful heat energy delivered to the load to the solar energy incident on the collector, for the honeycomb collector and the reference collector averaged over all the days is $33 \%$ and $28 \%$, respectively.

Table 3 shows the angle of incidence of the solar radiation on fifteenth day of each month of the year at the solar noon at Delhi. We observe that for the months of May, June, and July as the minimum angle of incidence is within $10^{\circ}$. For all other months the cylindrical honeycomb collector will have to be used with a mirror that can direct the beam towards the collector with smaller angle of incidence.

In the following paragraphs we have tried to explain the low emittance of the honeycomb for angle of incidence greater than $20^{\circ}$.

Consider a ray which is on the plane that divides the tube into two equal halves (symmetric plane) with incident angle of $60^{\circ}$ which hits a tube at its top edge (Figure $4(\mathrm{a})$ ). 


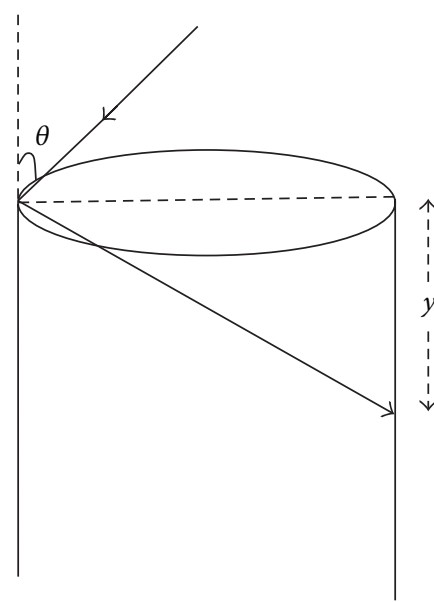

(a)

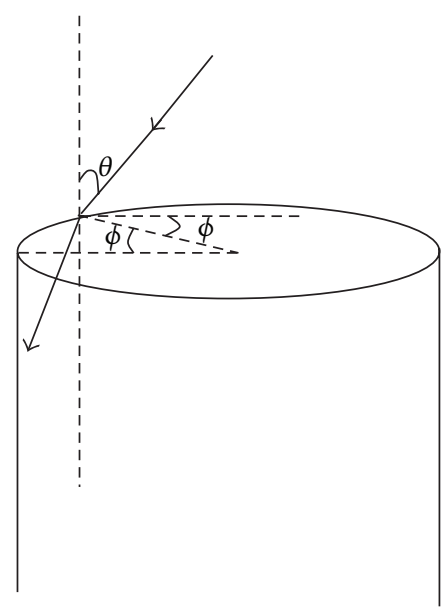

(b)

Figure 4: (a) Diagram showing the incident and reflected rays falling on the plane of symmetry and (b) incident and reflected rays on a plane off the plane of symmetry.

The vertical distance between its successive reflections, $y$, will be given by

$$
y=d \tan 30^{\circ} .
$$

Therefore the number of reflections suffered by the ray for the whole length of the tube will be

$$
n=\frac{L}{d \tan 30^{\circ}}=8
$$

The rays which are off the symmetric plane will suffer larger number of reflections as they travel down the tube. Consider the case shown in Figure 4(b) in which the ray with the same angle of incidence $(\theta)$ of $60^{\circ}$ hits the edge of a tube which has azimuth angle $(\phi)$ of $30^{\circ}$ as shown in the figure. For this case the projections of the successive rays on a horizontal plane would be an equilateral triangle. For this case

$$
y=d \cos 30^{\circ} \tan 30^{\circ}, \quad \text { giving } n=9 .
$$

Similarly, a ray with $\theta=60^{\circ}$ and $\phi=45^{\circ}$ gives $n=12$.

Thus the rays with larger angle of azimuth suffer a greater number of reflections resulting in low value of transmittance (defined as the ratio of transmitted to the incident solar energy).

The computation of actual value of transmittance can be very complex as the rays will suffer multiple reflections and refractions. An estimate for the value of transmittance can be obtained using the equation for steady state energy balance for the honeycomb collector, which is given as

$$
Q_{U}=E \tau(\theta)-Q_{\mathrm{LT}}-Q_{\mathrm{LB}} .
$$

The useful heat $Q_{U}$ delivered to the thermal load is computed using

$$
Q_{U}=m_{g} \cdot C_{g} \cdot\left(T_{g}(t)-T_{\text {in }}\right) .
$$

The input solar energy is obtained from

$$
E=\sum_{i=1}^{n} H_{i} \cdot A .
$$

The values of $H_{i}$ have been obtained from reference [18] and listed in Table 2.

The value of heat lost through the bottom of the collector plate, $Q_{L B}$, can be assumed negligible. The value of heat lost through top of the collector plate, $Q_{\mathrm{LT}}$, can be found using value of heat transfer coefficient for the gap $3.28 \mathrm{~mm}$ as listed in Table 1, and using the equation given below:

$$
\mathrm{Q}_{\mathrm{LT}}=h \cdot A \cdot\left\langle\left(T_{c}-T_{t}\right)\right\rangle \cdot \Delta t .
$$

Using all these values, the values of transmittance $\tau(\theta)$ can be computed at different times. The value for 10 am and 11 am has been listed in Table 2. We observe that the honeycomb layer has low values of transmittance when the angle of incidence is greater than $20^{\circ}$. For smaller values of angle of incidence the error in computation of transmittance would be larger as the value of $h$ as obtained in Section 2 will not be valid for higher range of temperatures. For a very small angle of incidence $\left(<10^{\circ}\right)$ the instantaneous transmittance may be nearly same as that of the reference collector.

\section{Conclusion}

The present investigations on cylindrical honeycombs with aspect ratio of 4.9, fabricated with transparent cellulose triacetate polymer sheets of thickness $0.1 \mathrm{~mm}$, have been conducted in two parts. The main conclusions of the investigations are the following.

The results of the first part are based on direct measurement of heat transfer coefficient for three gap thicknesses between the honeycomb and the collector plate and a reference collector which has a single cover plate. The cylindrical honeycomb layer is effective in suppressing the dissipative 
heat loss from the collector surface if the gap between the collector surface and the honeycomb is $3.3 \mathrm{~mm}$. For gaps which are larger or smaller than $3.3 \mathrm{~mm}$ the honeycomb is ineffective in convective heat loss suppression.

The second part of the investigations is a field experiment in which the gap between the honeycomb and the collector plate has been maintained at $3.25 \mathrm{~mm}$. The comparative temperature variation of the collector plate of the honeycomb collector and the reference collector without the honeycomb and with single cover plate reveals that the honeycomb collector can deliver substantially higher temperature ( 9 to $12^{\circ} \mathrm{C}$ ) to a thermal load of $2.18 \mathrm{~kJ} / \mathrm{K}$ from 12 noon to $2 \mathrm{pm}$. The overall energy conversion efficiency of the honeycomb collector has been found to be $\sim 33 \%$ which is $18 \%$ higher than the reference collector. This shows that the honeycomb layer is effective in enhancing the efficiency of the collector. A similar honeycomb arrangement with larger area can be used effectively in a solar cooker.

\section{Nomenclature}

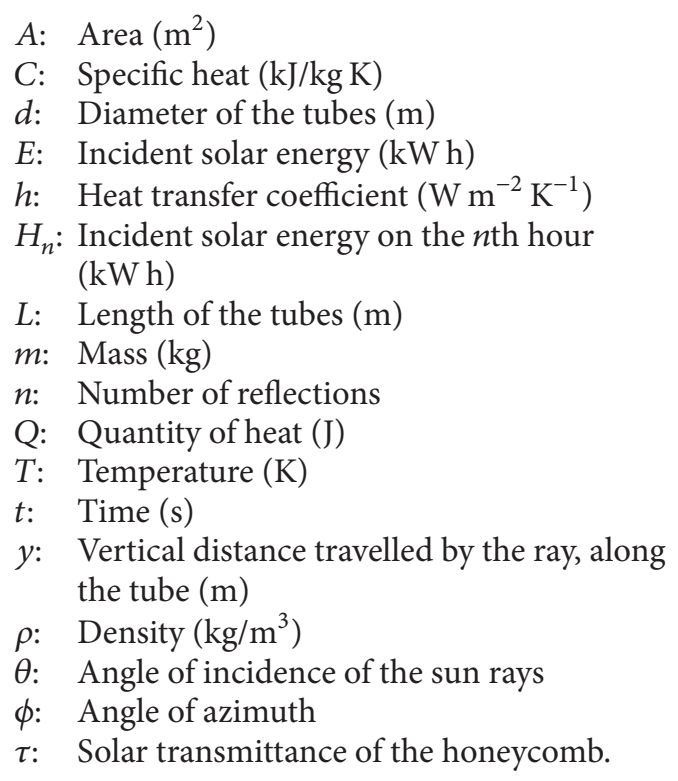

Subscripts
c: Collector plate
g: Gypsum
in: Initial
LT: Loss from top
LB: Loss from bottom
$U$ : Useful
$t$ : Cover plate.

\section{Conflict of Interests}

The authors declare that there is no conflict of interests regarding the publication of this paper.

\section{Acknowledgments}

The authors express gratitude for providing necessary facilities to Dr. Vishwajit Kadam, Secretary Bharati Vidyapeeth Trust, Pune, and the lab staff of Applied Science Department, BVCOE, New Delhi.

\section{References}

[1] F. Kreith and J. F. Kreider, Principles of Solar Engineering, McGraw-Hill, New York, NY, USA, 1978.

[2] P. T. Landsberg and G. Tonge, "Thermodynamic energy conversion efficiencies," Journal of Applied Physics, vol. 51, no. 7, p. R1, 1980.

[3] A. Goetzberger and M. Rommel, "Prospects for integrated storage collector systems in central Europe," Solar Energy, vol. 39, no. 3, pp. 211-219, 1987.

[4] N. D. Kaushika, R. A. Ray, and P. Priya, "A honeycomb solar collector and storage system," Energy Conversion and Management, vol. 30, no. 2, pp. 127-134, 1990.

[5] H. A. Zondag, "Flat-plate PV-thermal collectors and systems: a review," Renewable and Sustainable Energy Reviews, vol. 12, no. 4, pp. 891-959, 2008.

[6] I. L. Wong, P. C. Eames, and R. S. Perera, "A review of transparent insulation systems and the evaluation of payback period for building applications," Solar Energy, vol. 81, no. 9, pp. 1058-1071, 2007.

[7] N. D. Kaushika and K. S. Reddy, "Thermal design and field experiment of transparent honeycomb insulated integratedcollector-storage solar water heater," Applied Thermal Engineering, vol. 19, no. 2, pp. 145-161, 1999.

[8] O. Lalude and H. Buchberg, "Design and application of honeycomb porous-bed solar-air heaters," Solar Energy, vol. 13, no. 2, pp. 223-242, 1971.

[9] S. Zhang, Z. Wu, B. Yang, Z. Shen, and H. Ru, "A cylindrical glass honeycomb solar collector and its application," International Journal of Ambient Energy, vol. 6, no. 2, pp. 79-88, 1985.

[10] K. G. T. Hollands, "Honeycomb devices in flat-plate solar collectors," Solar Energy, vol. 9, no. 3, pp. 159-164, 1965.

[11] A. A. Ghoneim, "Performance optimization of solar collector equipped with different arrangements of square-celled honeycomb," International Journal of Thermal Sciences, vol. 44, no. 1, pp. 95-105, 2005.

[12] Z. Zhang, R. Zuo, P. Li, and W. Su, "Thermal performance of solar air collector with transparent honeycomb made of glass tube," Science in China E: Technological Sciences, vol. 52, no. 8, pp. 2323-2329, 2009.

[13] M. Dowson, D. Harrison, S. Craig, and Z. Gill, "Improving the thermal performance of single-glazed windows using translucent granular aerogel," International Journal of Sustainable Engineering, vol. 4, no. 3, pp. 266-280, 2011.

[14] H. Z. Abou-Ziyan and R. F. Richards, "Effect of gap thickness on a rectangular-cell compound-honeycomb solar collector," Solar Energy, vol. 60, no. 5, pp. 271-280, 1997.

[15] A. H. Abdullah, H. Z. Abou-Ziyan, and A. A. Ghoneim, "Thermal performance of flat plate solar collector using various arrangements of compound honeycomb," Energy Conversion and Management, vol. 44, no. 19, pp. 3093-3112, 2003.

[16] J. P. Holman, Heat Transfer, Tata McGraw-Hill Education, New Delhi, India, 2008. 
[17] J. A. Duffie and W. A. Beckman, Solar Engineering of Thermal Processes, John Wiley \& Sons, Mississauga, Canada, 2nd edition, 1991.

[18] A. Mani and S. Rangarajan, Solar Radiation over India, Allied Publishers, New delhi, India, 1982. 


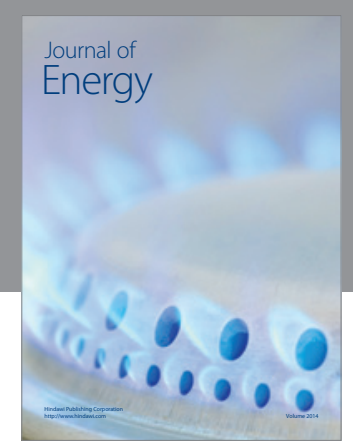

Journal of

Industrial Engineering
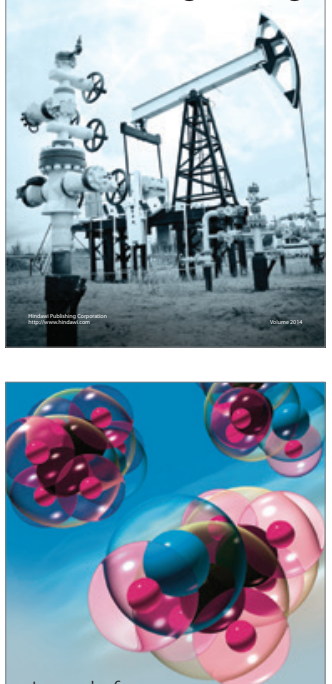

Fuels
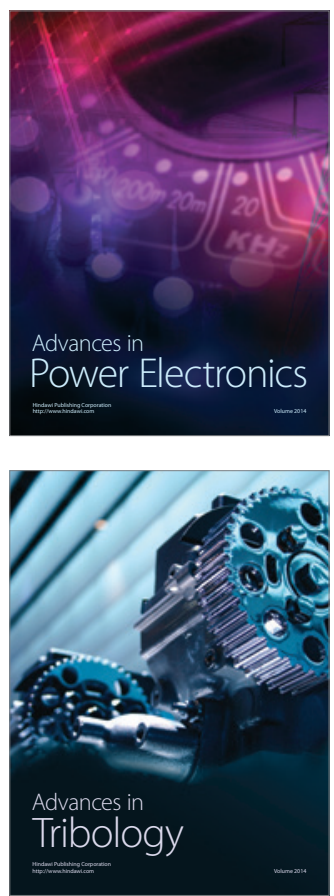

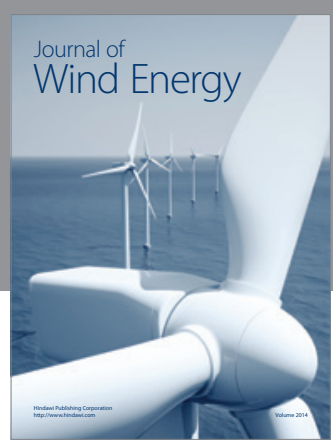

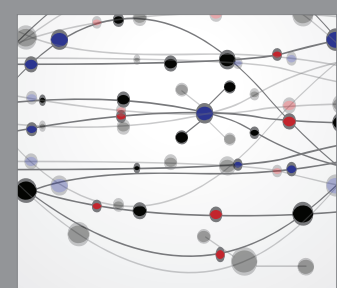

The Scientific World Journal

Submit your manuscripts at http://www.hindawi.com

Journal of

Structures
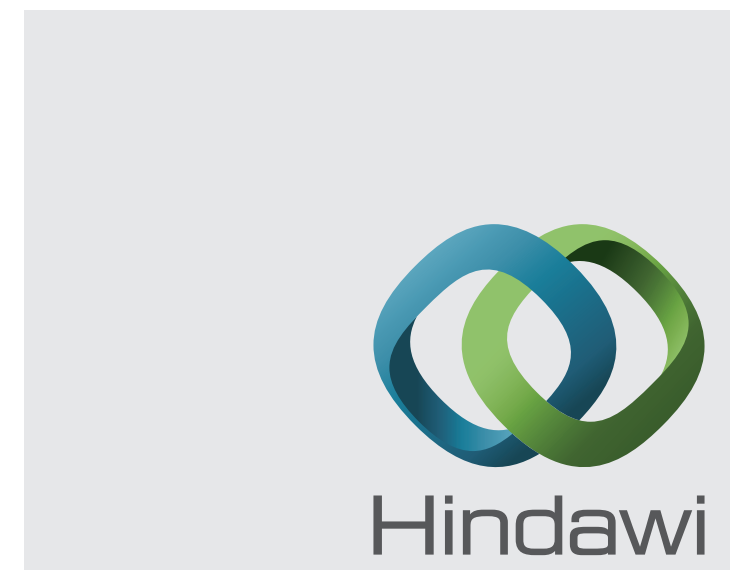

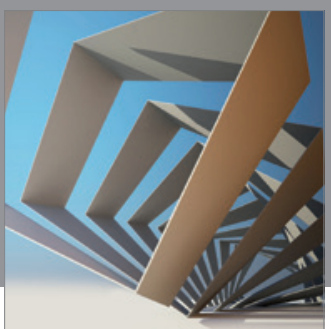

Rotating

Machinery
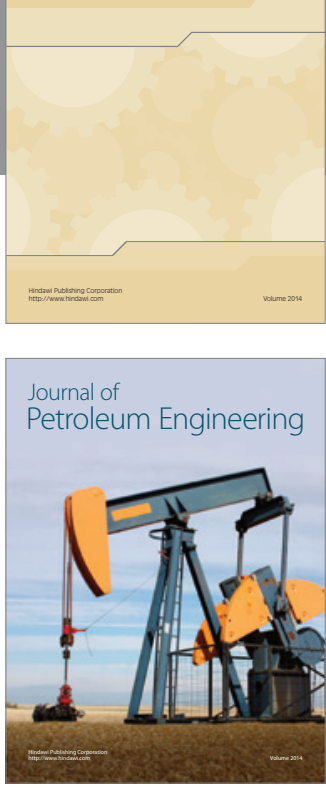

Journal of

Solar Energy
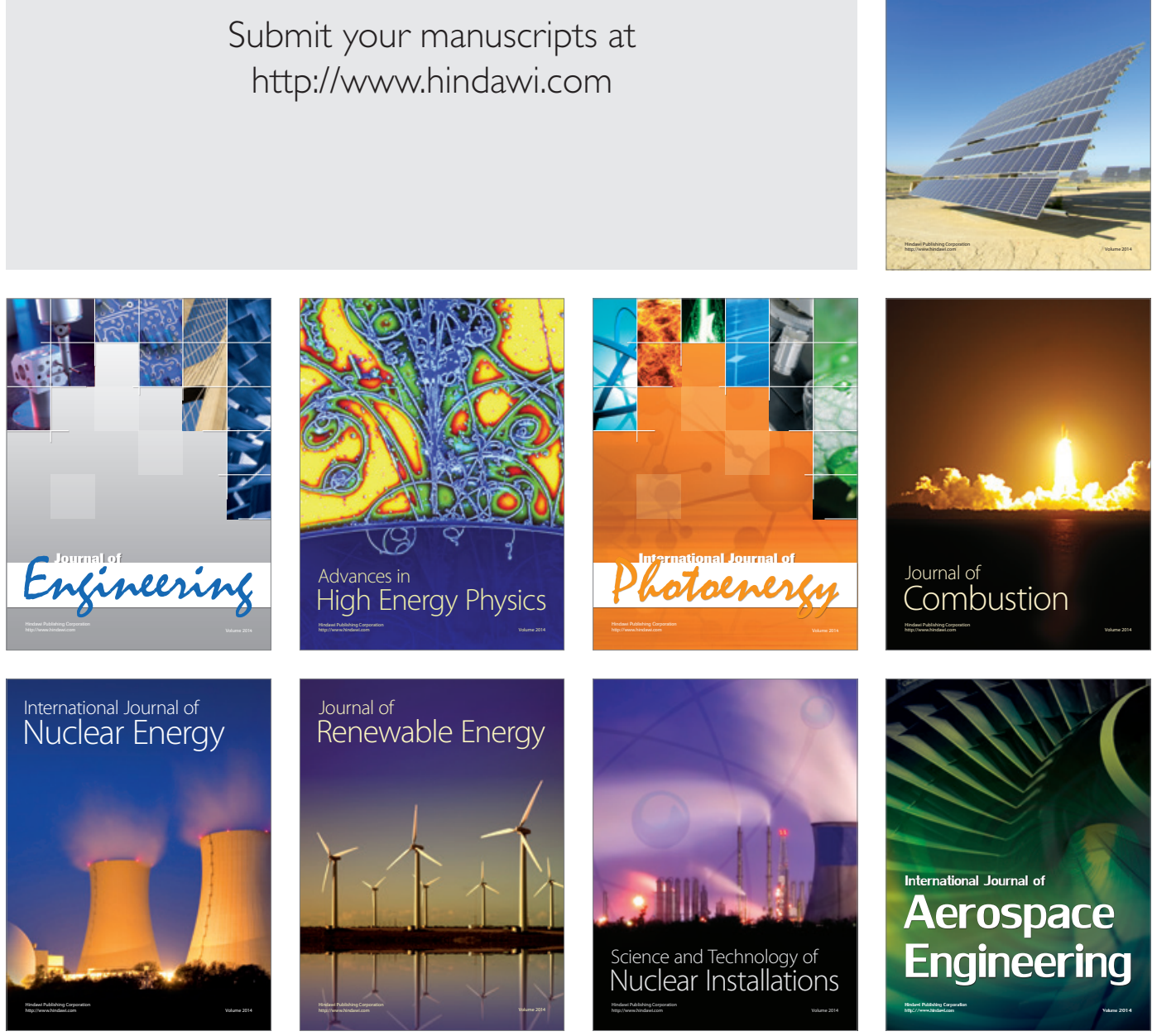